\title{
Encouraging vegetable intake as a snack among children: the influence of portion and unit size
}

\author{
Ellen van Kleef ${ }^{1, *}$, Ilse Bruggers ${ }^{1}$ and Emely de $\mathrm{Vet}^{2}$ \\ 'Wageningen University, Marketing and Consumer Behaviour Group, Hollandseweg 1, 6709 KN Wageningen, \\ The Netherlands: ${ }^{2}$ Wageningen University, Strategic Communication Group, Wageningen, The Netherlands
}

Submitted 15 July 2014: Final revision received 11 February 2015: Accepted 3 March 2015: First published online 30 April 2015

\begin{abstract}
Objective: People eat more unhealthy foods when served more (portion size effect) and when the food is served in larger units (unit size effect). The present study aimed to examine whether these effects can be used for the good: to increase vegetable consumption among children.

Design: A $2 \times 2$ between-subjects experiment was conducted at two schools. Pupils were presented in class with cucumber that varied both in unit size (one piece $v$. pre-sliced) and portion size (one-third $v$. two-thirds of a cucumber). Children ate ad libitum during the morning break and filled in a survey.

Setting: Primary schools in the centre of the Netherlands.

Subjects: Primary-school pupils ( $n$ 255) aged 8-13 years.

Results: Children ate $54 \%$ more cucumber when served a large compared with a smaller portion (difference of $49 \mathrm{~g} ; P<0.001$ ). Large units did not impact consumption $(P=0 \cdot 58)$, but were considered as less convenient to eat than small units $(P=0 \cdot 001)$.

Conclusions: Findings suggest that children's vegetable intake can be improved by serving larger portions in smaller-sized pieces.
\end{abstract}

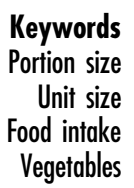

High fruit and vegetable intake is associated with reduced risk of future chronic diseases ${ }^{(1)}$. Despite the considerable evidence that eating vegetables has various health benefits, children's intake is less than recommended in many countries worldwide ${ }^{(2,3)}$.

Strategies are needed to increase vegetable intake among children. Traditional educational interventions may not be very successful and sometimes even countereffective. For example, research suggests that telling children to eat a certain food because it is good for them may actually lower taste evaluations and consumption ${ }^{(4)}$. Yet, alternative intervention strategies are necessary and environmental-level changes have been advocated as promising in encouraging healthy eating habits ${ }^{(5)}$.

In the present paper we examine such an environmental-level intervention by focusing on the portion and unit size of food. Many studies have shown that larger portions lead to higher intake without people compensating for this increased intake or reporting feeling more satisfied ${ }^{(6-8)}$. A key underlying mechanism driving the portion size effect is the unit size (i.e. the number of pieces into which a given amount of food is divided). A unit of food, such as a chocolate bar or piece of bread, represents the norm of what is acceptable or reasonable to eat in one go ${ }^{(9)}$. Experimental research shows that given equal energy and volumetric content, larger units of food tend to increase food consumption ${ }^{(10-12)}$. People have the tendency to complete the unit that they start to eat (i.e. completion compulsion) and even deem it less extraordinary if people eat larger units (e.g. one large chocolate bar) compared with when they would eat the exact same amount from smaller units (e.g. five small chocolates) ${ }^{(13)}$.

A key question to ask is whether factors such as portion and unit size, known to encourage consumption of highenergy, low-nutrient-dense foods, can effectively be applied to encourage consumption of healthier foods. Therefore, the aim of the present study was to examine whether providing larger portions of vegetables in larger units would increase their consumption as a snack among elementary-school children during a break at school.

In the study we investigate whether unit and portion size can be exploited to seduce children to eat more snack vegetables. We expected consumption in children to increase when portions are doubled. We furthermore hypothesized that an increase in consumption would occur when the unit size of the snack vegetable was large. Finally, we have no prior hypothesis about a potential 
interaction effect because although larger units tend to increase consumption, sliced vegetables may be more appealing to children because they are easier and tidier to eat ${ }^{(14,15)}$.

\section{Methods}

\section{Participants, design and procedure}

We carried out a two (portion size: small, large) by two (unit size: small, large) between-subjects experiment ( $n$ 255; 142 females, 112 males, gender unknown for one participant) at two primary schools in the centre of the Netherlands. Each school participated with six classes each, ranging from grade 5 (with 8-9-year-old children) to grade 8 (11-12-year-old children). Classes were assigned to the experimental conditions. So, all children in one class were assigned to the same condition to prevent awareness of the experimental manipulations.

The study was presented as a taste test of cucumbers. Based on a small-scale pilot test,* cucumber was chosen as a generally familiar and well-liked vegetable among children. The study was conducted in the children's own classroom just before their morning break at about 09.30 hours, reflecting the natural snack moment in schools. Children sat behind their usual desk and each child was presented with a plastic plate with cucumber.

The serving of the large portion size of cucumber consisted of two-thirds of a cucumber and was on average 248 (SD 14) g per portion. The small portion of cucumber consisted of about one-third of a cucumber and weighed on average 127 (SD 11) g per portion. In the large unit size conditions, these cucumbers were served in one piece. For the small unit size conditions, the portion was cut in either six pieces in the small portion or twelve pieces in the large portion.

Before they could start eating, children first completed questions on relevant control variables, i.e. age, gender, appetite before consumption and general cucumber liking. Next, children were told they could start eating and it was stressed that the children could decide for themselves how much they wanted to eat. No refills were served. When they felt that they were done eating, instructions were given to put any leftovers in a sandwich bag in front of them. Next, they continued with the last part of the questionnaire that assessed estimations of the amount of food consumed, opinions about the serving size and perceived difficulties with eating.

Data collection took place in June 2013. Two classes participated per day, which means that data collection was finished after six school days. The study was conducted according to the guidelines laid down in the Declaration of

\footnotetext{
* This pilot test among fifty-eight children with an average age of 8.5 (SD 0.6) years showed that almost 64\% (thirty-seven children) selected cucumber instead of bananas as a snack during the morning break at a
} junior science event at the university.
Helsinki and all procedures were approved by the Social Sciences Ethical Committee of Wageningen University. Parents of the children in the participating classes received a letter with detailed information about the study and were asked to indicate when they did not allow their children to participate (passive consent).

\section{Measures}

The key dependent variable was children's consumption of cucumber in grams. Each individual portion of cucumber was weighed before consumption. Unbeknownst to the children, leftover cucumber was weighed afterwards to calculate the grams of cucumber eaten.

Cucumber liking was measured before consumption by two items: 'The cucumber looks tasty' and 'I like cucumbers' $(\alpha=0 \cdot 81)$. Feelings of hunger and desire were measured by three items: 'I am hungry', 'I think I can finish it all' and 'I cannot wait to start' $(\alpha=0 \cdot 76)$. Scores were averaged into a single appetite scale. Also before eating, perceptions of what the children considered a normal portion of cucumber to eat was assessed with the item 'There is more on my plate than I normally snack'.

After consumption, children responded to the item 'I ate more than I would usually snack'. Eating difficulty was assessed by the single item 'It was hard to eat the cucumber'. All statements were preceded by the phrase 'Show your opinion by crossing the correct box' and were scored on a scale from 1 ('not at all') to 5 ('very much'). Smiley faces showing 'thumbs up' or 'thumbs down' were added to the response categories to make the questionnaire child friendly.

Finally, children were also asked to indicate (i) the amount of cucumber they ate and (ii) the amount they think is an appropriate amount to eat as a snack. A scaled picture of a cucumber accompanied by a tape measure was presented to them and children were asked to draw a line and colour in the area (i) they thought to have eaten and (ii) what they would consider appropriate. Consumption and consumption norm estimations are expressed in centimetres. $\dagger$ Finally, children were given the opportunity to write down anything they wanted about the study in an empty box at the end of the questionnaire.

\section{Data analysis}

We checked for differences across conditions regarding age, gender, appetite and liking of cucumber using ANOVA and $\chi^{2}$ analysis. Consumption data were also checked for normality of distribution (skewness and kurtosis). Statistical analysis of the consumed cucumber data was performed using ANCOVA with grams of cucumber consumed as the dependent variable and portion size (small $v$. large) and unit size (small $v$. large) as between-subjects factors. Data were analysed using the

$\dagger$ Please note that the centimetres do not refer to actual centimetres of cucumber, but reflect the centimetres of the scaled cucumber picture. 
Table 1 Cucumber intake and ratings as a function of portion and unit size among pupils $(n 255)$ aged 8-13 years from two primary schools in the centre of the Netherlands, June 2013

\begin{tabular}{|c|c|c|c|c|c|c|c|c|c|c|c|}
\hline & \multicolumn{4}{|c|}{$\begin{array}{l}\text { Large portion size } \\
\qquad(n 127)\end{array}$} & \multicolumn{4}{|c|}{$\begin{array}{l}\text { Small portion size } \\
\quad(n 127)\end{array}$} & \multirow{3}{*}{$\begin{array}{l}\text { Main effect } \\
\text { portion size }\end{array}$} & \multirow{3}{*}{$\begin{array}{l}\text { Main effect } \\
\text { unit size }\end{array}$} & \multirow{3}{*}{$\begin{array}{c}P \text { value for } \\
\text { interaction effect }\end{array}$} \\
\hline & \multicolumn{2}{|c|}{$\begin{array}{l}\text { Large unit } \\
\text { size }(n 63)\end{array}$} & \multicolumn{2}{|c|}{$\begin{array}{l}\text { Small unit } \\
\text { size }(n 64)\end{array}$} & \multicolumn{2}{|c|}{$\begin{array}{l}\text { Large unit } \\
\text { size }(n 64)\end{array}$} & \multicolumn{2}{|c|}{$\begin{array}{l}\text { Small unit } \\
\text { size }(n 63)\end{array}$} & & & \\
\hline & Mean & SD & Mean & SD & Mean & SD & Mean & SD & & & \\
\hline \multicolumn{12}{|l|}{ Randomisation checks* } \\
\hline Appetite-scale & 3.4 & 1.0 & 3.7 & 1.0 & 3.5 & 1.1 & $3 \cdot 8$ & 1.0 & 0.38 & 0.02 & 0.84 \\
\hline Cucumber liking & 4.2 & $1 \cdot 1$ & 4.2 & $1 \cdot 1$ & $4 \cdot 1$ & $1 \cdot 1$ & 4.4 & $1 \cdot 1$ & 0.90 & 0.28 & 0.27 \\
\hline Age & $10 \cdot 4$ & 1.6 & $10 \cdot 0$ & 1.0 & 9.7 & 1.0 & $10 \cdot 3$ & 1.3 & 0.30 & 0.35 & $<0.01$ \\
\hline \multicolumn{12}{|l|}{ Pre-consumption ratings* } \\
\hline $\begin{array}{l}\text { There is more on my plate than I } \\
\text { normally snack }\end{array}$ & 3.5 & $1 \cdot 3$ & $3 \cdot 2$ & 1.5 & $2 \cdot 9$ & 1.4 & $3 \cdot 1$ & 1.4 & 0.046 & 0.35 & $0 \cdot 19$ \\
\hline \multicolumn{12}{|l|}{ Food intake } \\
\hline $\begin{array}{l}\text { Grams of cucumber consumed } \\
\text { Post-consumption ratings }{ }^{\star}\end{array}$ & $136 \cdot 6$ & $95 \cdot 6$ & $142 \cdot 1$ & $95 \cdot 7$ & $84 \cdot 2$ & $51 \cdot 3$ & $96 \cdot 7$ & 41.9 & $<0.001$ & 0.58 & 0.87 \\
\hline It was hard to eat the cucumber & 2.9 & 1.4 & $2 \cdot 2$ & 1.5 & $2 \cdot 3$ & 1.4 & 1.8 & 1.3 & 0.01 & 0.001 & 0.92 \\
\hline I ate more than I would usually snack & 3.5 & 1.4 & $2 \cdot 8$ & 1.5 & $2 \cdot 2$ & 1.3 & $2 \cdot 6$ & 1.4 & $<0.001$ & 0.08 & $<0.01$ \\
\hline $\begin{array}{l}\text { Centimetres of cucumber considered } \\
\text { an appropriate amount to eat }\end{array}$ & 3.5 & $2 \cdot 7$ & $4 \cdot 3$ & $2 \cdot 6$ & $3 \cdot 7$ & $2 \cdot 1$ & 4.5 & $2 \cdot 4$ & 0.83 & 0.09 & 0.71 \\
\hline $\begin{array}{l}\text { Estimation of centimetres of } \\
\text { cucumber eaten at picture }\end{array}$ & $7 \cdot 1$ & 3.9 & $5 \cdot 6$ & 3.3 & 3.7 & $2 \cdot 1$ & $4 \cdot 3$ & $2 \cdot 1$ & $<0.001$ & $<0.01$ & $<0.001$ \\
\hline
\end{tabular}

*Numbers (except age and centimetres of cucumber) represent mean scores on each of the scales (5-point scales).

†In this analysis, the covariate 'grams of cucumber eaten' was included to correct for true consumption.

statistical software package IBM SPSS Statistics 19.0. A significance level of $P<0.05$ was used. Effect sizes $\left(\eta_{\mathrm{p}}^{2}\right)$ are reported for statistically significant outcome measures.

\section{Results}

\section{Descriptive information and randomisation check}

The average age of the sample was 10.1 (SD 1.3) years (range $8-13$ years). Gender was equally balanced across conditions and participants across conditions did not differ in cucumber liking (all $P>0 \cdot 27$ ). However, there was a difference across conditions in age (interaction unit size by portion size: $\left.F(1,250)=15 \cdot 0 ; P<0 \cdot 01, \eta_{\mathrm{p}}^{2}=0 \cdot 04\right)$. ANOVA with unit size and package size as independent variables and the appetite scale as dependent variable revealed a main effect of unit size $\left(F(1,251)=5 \cdot 4, P=0 \cdot 02, \eta_{\mathrm{p}}^{2}=0.02\right)$ in that children being presented with small units of cucumber had a stronger appetite to eat (mean 3.8 (SD 1.0)) than children being presented with large units (mean 3.5 (SD 1.1)). No other main or interaction effects were observed. Therefore, in all analyses (see Table 1), we included age and appetite as covariates to control for influence.

\section{Amount of cucumber consumed}

On average, children ate 115 (SD 79) g of cucumber. Consumption of cucumber was normally distributed (skewness $=0 \cdot 28 ; \quad$ kurtosis $=-0 \cdot 75$ ). Thirty children in total did not eat any of the cucumber. These noneaters were equally distributed across conditions
( $P=0 \cdot 18$; Fisher's exact test). Almost half of all children (127 children out of 255 ) finished the entire portion that was served to them. These 'plate cleaners' were also equally distributed across conditions $(P=0.51$; Fisher's exact test).

ANCOVA with unit size and package size as independent variables and grams of cucumber consumed as dependent variable revealed a main effect of portion size $\left(F(1,248)=47 \cdot 5, P<0 \cdot 001, \eta_{\mathrm{p}}^{2}=0 \cdot 16\right)$ in that participants in the large portion size conditions ate more than participants in the small portion size conditions (large portion size: mean 139.4 (SD 95.3) g; small portion size: mean 90.4 (SD 47.1) g). So, participants being presented with the large portion size ate about $54 \%$ more cucumber relative to the small portion size. No main effect of unit size $\left(F(1,248)=0.3, \quad P=0.58, \quad \eta_{\mathrm{p}}^{2}=0.001\right)$ or interaction effects between unit and portion size $(F(1,248)=0 \cdot 03$, $\left.P=0.87, \eta_{\mathrm{p}}^{2}<0 \cdot 001\right)$ on amount of cucumber consumed was observed. After excluding from the analysis all participants who finished their plate (plate cleaners), we still observed the effect of portion size on intake $(P<0 \cdot 001)$. Similarly, when excluding non-eaters from the analysis, the portion size effect was still there $(P<0 \cdot 001) *$

\footnotetext{
* We also ran the analysis with eating difficulty as an additional covariate to control for the large difference in unit size in the study. Results showed no differences in significance patterns of the key dependent variable, grams of cucumber consumed. As a covariate in this analysis, eating difficulty had a marginal effect on grams of cucumber consumed $(F(1,246)=2 \cdot 8, P=0 \cdot 097)$.
} 


\section{Effects on pre-and post-consumption evaluations of cucumber}

There was a significant main effect of portion size on perceptions of the amount served $(F(1,246)=4 \cdot 0, P=0 \cdot 046$, $\left.\eta_{\mathrm{p}}^{2}=0.02\right)$, but not of unit size $(F(1,246)=0.9, P=0.35$, $\left.\eta_{\mathrm{p}}^{2}=0.004\right)$ or of the interaction between unit size and portion size $\left(F(1,246)=1 \cdot 7, P=0 \cdot 19, \eta_{\mathrm{p}}^{2}=0 \cdot 007\right)$. Children who were served the large portion more strongly reported that they were served a larger portion than they would normally snack (mean 3.3 (SD 1.4)) compared with children who were served a small portion (mean $3 \cdot 0$ (SD 1.4)).

Main effects of portion size $(F(1,247)=6 \cdot 6, \quad P=0 \cdot 01$, $\left.\eta_{\mathrm{p}}^{2}=0.03\right)$ and unit size $\left(F(1,247)=11 \cdot 8, P=0.001, \eta_{\mathrm{p}}^{2}=0.05\right)$ on eating difficulty were found, but no interaction ( $F$ $\left.(1,247)=0.01, \quad P=0.92, \quad \eta_{\mathrm{p}}^{2}<0.001\right) \quad$ was observed. Children felt that larger portions and units were harder to eat.

Both portion and unit size did not affect consumption norms of what children considered to be an appropriate amount to eat (main effect portion size: $F(1,222)=0.05$, $P=0.83, \eta_{\mathrm{p}}^{2}<0 \cdot 001$; main effect unit size: $F(1,222)=2 \cdot 8$, $P=0.09, \eta_{\mathrm{p}}^{2}=0.013$; interaction: $F(1,222)=0 \cdot 1, P=0.71$, $\left.\eta_{\mathrm{p}}^{2}=0 \cdot 001\right)$.

Significant main effects of portion size and unit size, and a significant interaction effect, were found on children's estimation of their own consumption in centimetres of cucumber. In this analysis, the actual amount of cucumber eaten in grams was added as a covariate to account for true consumption. Irrespective of the actual amount eaten, children felt they ate more cucumber when served a large portion (main effect portion size: $F(1,234)=16 \cdot 8$, $\left.P<0 \cdot 001, \eta_{\mathrm{p}}^{2}=0 \cdot 07\right)$ or in large units (main effect unit size: $\left.F(1,234)=10 \cdot 1, P<0 \cdot 01, \eta_{\mathrm{p}}^{2}=0 \cdot 04\right)$. There was an interaction effect between portion and unit size $\left(F(1,234)=12 \cdot 8, P<0 \cdot 001, \eta_{\mathrm{p}}^{2}=0.05\right)$ in that children in the large portion size and unit size condition felt that they had eaten the most cucumber.

Our unit and portion size manipulations impacted scores on the item 'I ate more than I would usually snack'. On average, children felt they ate more than they would usually do in the large portion size conditions (main effect portion size: $\left.F(1,246)=23 \cdot 1, P<0 \cdot 001, \eta_{\mathrm{p}}^{2}=0 \cdot 09\right)$. No main effect of unit size was observed $\left(F(1,246)=3 \cdot 2, P=0 \cdot 08, \eta_{\mathrm{p}}^{2}=0 \cdot 013\right)$. There was an interaction effect between portion and unit size $\left(F(1,246)=8 \cdot 4, P<0 \cdot 01, \eta_{\mathrm{p}}^{2}=0 \cdot 03\right)$ in that children in the large portion size and unit size condition most strongly felt that they ate more than they would normally do.

\section{Discussion}

The present study showed that serving more vegetables increases their consumption as a snack by about $54 \%$ among primary-school children. Intake of cucumber increased from $90 \mathrm{~g}$ to about $139 \mathrm{~g}$, which is approximately two-thirds of the recommended daily intake of vegetables in the Netherlands (150-200 g).
A recent review of 104 portion size studies among a wide variety of consumers, types of foods and situations showed that doubling of portion size leads to an average consumption increase of $35 \%$, although the effect is weaker among children, people with a high BMI and women $^{(16)}$. Our findings extend this previous research by showing that the same results may be achieved in children when presented a healthy snack.

Only a few studies have investigated the portion size effect for healthy products among children. One study showed that doubling of portions led to an increase of vegetable intake by $37 \%$ and an increase of fruit intake by $70 \%{ }^{(17)}$, although effects were limited to children who liked the particular food. Similarly, doubling the portion size of fruit and vegetable side dishes added to a meal resulted in a $43 \%$ increased intake of the fruit side dish, although no effect on intake was found for doubling vegetable side dishes ${ }^{(18)}$. In other studies, it was found that adding more vegetables to a meal, for example as a firstcourse vegetable soup or as a hidden ingredient in pasta sauce, are effective strategies to increase vegetable consumption and decrease meal energy intake due to substitution of other energy-dense meal components ${ }^{(19-22)}$. Most of these studies, however, were conducted in laboratory meal settings with small samples of young children aged $4-6$ years. The portion size effect as a driver of healthy consumption has not well been investigated in a natural snacking situation among older children.

Moreover, compared with the portion size effect, the unit size effect has received even less attention. While there have been several studies demonstrating that larger units increase consumption, these studies primarily used unhealthy foods, such as cookies and candy ${ }^{(10,11,13)}$. Interestingly, in a study where 9-12-year-olds indicated their liking for snack vegetables it was suggested that children preferred to be served vegetables sliced in small units, which would actually undermine the unit size effect $^{(14)}$. Moreover, little is known about how the effects of portion and unit size combine to impact children's consumption of vegetables as a snack.

Although portion size did influence consumption, serving larger units seemed ineffective in increasing intake in the present study. It may be that serving a larger unit unjustly created the feeling that children had eaten more (even when actual consumption was accounted for). Moreover, pre-slicing did not alter perceptions of how much food is appropriate to eat and available on the plate before eating, but did influence eating convenience. In line with a study by Olsen et al. ${ }^{(14)}$, pre-sliced foods were perceived as more convenient to eat and should therefore be favoured over serving larger units. Despite the fact that the unit size effect has been replicated in various studies on unhealthy food intake ${ }^{(10,11,13)}$, more research is needed to explore conditions under which the unit size effect takes place. A potential influencing factor could be the contrast between small and large unit sizes of the food, as 
this has not been constant across studies. Some unit sizes may make eating more difficult, although in the present study eating difficulty had only a marginal effect on how much children ate.

\section{Strengths and limitations}

The present study has some strengths and limitations that need to be acknowledged. Two strengths of the study are the focus on actual eating of snacks in a natural school setting and the large sample size. Nevertheless, as the experiment was conducted in the classroom in which children ate in groups, group dynamics or social influences may have played a role. When being presented with a larger portion size, children felt they ate more than they would usually do. Importantly, the present study investigated only immediate effects on consumption. Future research may also examine potential (negative) delayed effects. It could be that if children perceive that they ate a lot of healthy foods, they may compensate for this later on by eating less (healthy foods) or by eating more unhealthy foods. Furthermore, almost half of the children finished their portion while at the same time no refills were allowed. It is unclear how this may have impacted results. For example, plate cleaners in small portion size conditions may have wanted to eat more, contrary to children in large portion size conditions. Future research could examine the effect of allowing participants to refill their plate as many times as desired.

\section{Implications}

The present study has some implications for the development of nutritional advice and interventions to encourage consumption of fruit and vegetables. The key message is to offer larger portions, preferably cut in smaller pieces. For example, presenting children with larger bowls of cucumber, carrots or other raw vegetables and fruit could encourage greater consumption. In this way, children will eat more without verbal encouragement or 'pushing' them to eat. We used cucumber to illustrate the influence of portion and unit size cues in consumption in the present study. Although it is likely that our results also apply for other fruits and vegetables, future research could study the generalizability of our findings. Future research also should establish the optimal size of a portion: we used a relatively large portion size in our study in order to allow for variation in consumption. Yet a potential downside of serving larger portions is that children leave vegetables uneaten and food will be wasted. Hence, it is important to identify the optimal portion size a child is comfortable with.

To conclude, the present study showed that children eat more from a healthy vegetable snack when served more, but not more when served in larger pieces.

\section{Acknowledgements}

Acknowledgements: The authors thank the children and teachers of the schools for participation in this project. Financial support: This research received no specific grant from any funding agency in the public, commercial or notfor-profit sectors. Conflict of interest: None. Authorship: All authors contributed to the design of the study and critical revision of the manuscript. I.B. was responsible for data collection. E.v.K. carried out the statistical analyses and drafted the manuscript. All authors read and approved the final manuscript. Ethics of human subject participation: The Social Sciences Ethical Committee of Wageningen University approved the study.

\section{References}

1. Slavin JL \& Lloyd B (2012) Health benefits of fruits and vegetables. Adv Nutr 3, 506-516.

2. Guenther PM, Dodd KW, Reedy J et al. (2006) Most Americans eat much less than recommended amounts of fruits and vegetables. J Am Diet Assoc 106, 1371-1379.

3. Van Rossum CTM, Fransen HP, Verkaik-Kloosterman J et al. (2011) Dutch National Food Consumption Survey 2007-2010: Diet of Children and Adults Aged 7 to 69 years. Bilthoven: National Institute for Public Health and the Environment (RIVM).

4. Maimaran M \& Fishbach A (2014) If it's useful and you know it, do you eat it? Preschoolers refrain from instrumental food. J Consum Res 41, 642-655.

5. De Vet E, De Ridder DTD \& De Wit J (2011) Environmental contributors to childhood overweight and obesity: a systematic review of reviews. Obes Rev 12, e130-e142.

6. Ello-Marin JA, Ledikwe JH \& Rolls BJ (2005) The influence of food portion size and energy density on energy intake: implications for weight management. Am J Clin Nutr 82, 1 Suppl., 236S-241S.

7. Fisher JO \& Kral TV (2008) Super-size me: portion size effects on young children's eating. Physiol Behav 94, 39-47.

8. Van Kleef E, Shimizu M \& Wansink B (2013) Just a bite: considerably smaller snack portions satisfy delayed hunger and craving. Food Qual Prefer 27, 96-100.

9. Geier AB, Rozin P \& Doros G (2006) Unit bias. A new heuristic that helps explain the effect of portion size on food intake. Psychol Sci 17, 521-525.

10. Marchiori D, Waroquier L \& Klein O (2011) Smaller food item sizes of snack foods influence reduced portions and caloric intake in young adults. $J$ Am Diet Assoc 111, 727-731.

11. Marchiori D, Waroquier L \& Klein O (2012) 'Split them!' Smaller item sizes of cookies lead to a decrease in energy intake in children. J Nutr Educ Behav 44, 251-255.

12. Wansink B, Payne CR \& Shimizu M (2011) The 100-calorie semi-solution: sub-packaging most reduces intake among the heaviest. Obesity (Silver Spring) 19, 1098-1100.

13. Van Kleef E, Kavvouris C \& Van Trijp HCM (2014) The unit size effect of indulgent food: how eating smaller sized items signals impulsivity and makes consumers eat less. Psychol Health 29, 1081-1103.

14. Olsen A, Ritz C, Kramer L et al. (2012) Serving styles of raw snacks vegetables. What do children want? Appetite 59, $556-562$. 
15. Wansink B, Just DR, Hanks AS et al. (2013) Pre-sliced fruit in school cafeterias: children's selection and intake. Am J Prev Med 44, 477-480.

16. Zlatevska N, Dubelaar C \& Holden SS (2014) Sizing up the effect of portion size on consumption: a metaanalytic review. J Mark 78, 140-154.

17. Mathias KC, Rolls BJ, Birch LL et al. (2012) Serving larger portions of fruits and vegetables together at dinner promotes intake of both food among young children. $J$ Acad Nutr Diet 112, 266-270.

18. Kral TV, Kabay AC, Roe LS et al. (2010) Effects of doubling the portion size of fruit and vegetable side dishes on children's intake at a meal. Obesity (Silver Spring) 18, 521-527.
19. Leahy KE, Birch LL, Fisher JO et al. (2008) Reductions in entree energy density increase children's vegetable intake and reduce energy intake. Obesity (Silver Spring) 16, 1559-1565.

20. Rolls BJ, Roe LS \& Meengs JS (2010) Portion size can be used strategically to increase vegetable consumption in adults. Am J Clin Nutr 91, 913-922.

21. Spill MK, Birch LL, Roe LS et al. (2010) Eating vegetables first: the use of portion size to increase vegetable intake in preschool children. Am J Clin Nutr 91, 1237-1243.

22. Spill MK, Birch LL, Roe LS et al. (2011) Serving large portions of vegetable soup at the start of a meal affected children's energy and vegetable intake. Appetite 57, 213-219. 